\title{
Hypersensitivity pneumonitis in a technician using Pauli's reagent
}

\author{
W V EVANS AND A SEATON \\ From Llandough Hospital, Penarth, South Glamorgan, UK
}

\begin{abstract}
A technician working in a medical laboratory used a spray of sodium diazobenzenesulphate (Pauli's reagent) in chromatography. She developed a respiratory illness with both airways obstruction and radiographic and physiological evidence of interstitial pneumonitis. An occupational type of challenge test was followed by both immediate and late bronchial obstructive responses, by a fall in arterial oxygen tension, and by increased radiographic shadowing. Histology of a lung biopsy specimen, a low serum C3, and a positive skin prick test to the reagent suggested that the illness was a hypersensitivity reaction to Pauli's reagent.
\end{abstract}

Pauli's reagent is the sodium salt of diazobenzenesulphonic acid, which is produced by the reaction between cold sulphanilic acid, hydrochloric acid, and sodium nitrite. The sodium salt of the relatively unstable diazobenzenesulphonic acid is formed by adding sodium carbonate. The reagent is widely used in laboratories throughout the world for identifying aryl amines and phenols. This patient was using the reagent as a spray in chromatography work.

\section{Case history}

A 33-year-old medical school laboratory technician first developed retrosternal discomfort in 1969. She was released from work for a week, prescribed an antibiotic, and her symptoms disappeared. In 1974 she developed further chest discomfort associated with a non-productive cough. Her symptoms gradually progressed, and by the summer of 1977 she had become breathless on moderate exertion. Eventually she related her cough and dyspnoea to the chemicals, and in particular the spray, used at her work. At this time she was referred for further investigation.

Detailed inquiry into her work showed regular, twice weekly, use of Pauli's reagent (fig 1). She mixed the cold sulphanilic and hydrochloric acids with sodium nitrite on an open bench, then placed the mixture in a refrigerator for ten minutes before adding the sodium carbonate. The reagent was immediately sprayed on to chromatography

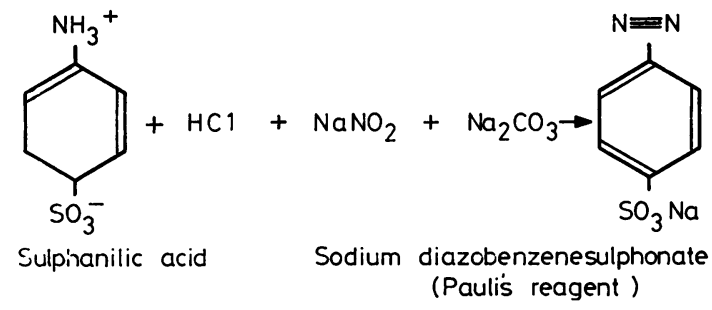

Fig 1 Reaction producing Pauli's reagent.

plates in a fume cupboard. A paper face mask was used throughout this procedure, which she performed for two years before she developed any symptoms. In 1969 her first attack of retrosternal discomfort followed a period of increased exposure to the reagent, when the fume cupboard was found to be defective. Nitroaniline was substituted for the sodium nitrite from 1972 until 1974, and during this period she was symptom free; thereafter the original process was used, and her symptoms returned.

There was no relevant past medical history. She had not been exposed to birds, and did not smoke cigarettes. Physical examination was normal. The chest radiograph, however, showed a fine nodular shadowing at both lung bases. Full blood count was normal without eosinophilia. The sedimentation rate was $37 \mathrm{~mm} / \mathrm{h}$ Westergren.

Liver function test results were normal and the DAT and ANF were negative. Protein electrophoresis showed an increase in gammaglobulin. 
Precipitating antibodies to Aspergillus fumigatus, $A$ niger, Micropolyspora faeni, as well as budgerigar and pigeon serum and droppings were absent. Sputum did not contain allergic stigmata (Sanerkin and Evans, 1965). Skin prick tests to house dust extract, Dermatophagoides pteronyssinus and mixed grass pollen were positive with an immediate weal and flare response. Lung function test results showed a restrictive pattern with a reduced carbon monoxide transfer factor (table).

To make a diagnosis it was decided to perform an occupational-type challenge test and a drill biopsy. The patient gave consent to these procedures after full explanation and was challenged with the chemicals and spray, following the same procedure as that used at her work. Peak expiratory flow rates were monitored at 15-minute intervals for the first hour, and hourly thereafter (fig 2). Lung volumes and transfer factor measurements were repeated after four hours (table). There was both an immediate and late (eight hours) fall in PEFR, and 17 hours after the challenge her sleep was disturbed by dyspnoea. Examination of her chest showed widespread inspiratory crackles, and a chest radiograph (fig 3) showed an increase in the nodular shadowing. The PEFR during this episode was $240 \mathrm{l} / \mathrm{min}$, a value lower than any previous measurement. She was hypoxaemic with a $\mathrm{PaO}_{2} 7.5 \mathrm{kPa}(56 \mathrm{mmHg})$, $\mathrm{PaCO}_{2} 4.5 \mathrm{kPa}(34 \mathrm{mmHg})$, and $\mathrm{pH}$ 7.42. Dyspnoea was relieved by treatment with $40 \%$ oxygen via a Ventimask.

A percutaneous drill biopsy was performed 24 hours after the challenge-the histology (fig 3) showed an interstitial mononuclear cell infiltrate with lymphoid foci, without germinal centres, and prominence of type 2 alveolar lining cells some of which were desquamated. No epithelioid cell granulomas were seen, but a very occasional giant cell was present. There was a slight increase in collagen in intra-alveolar septa, but there was no

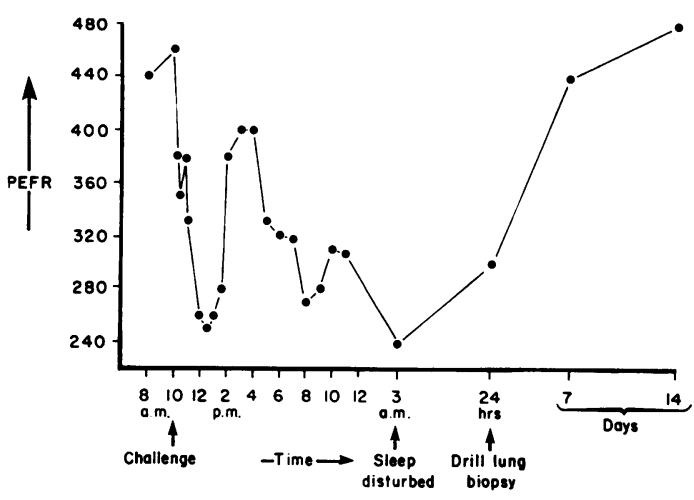

Fig 2 Peak expiratory flow rates following occupational type challenge test to Pauli's reagent.

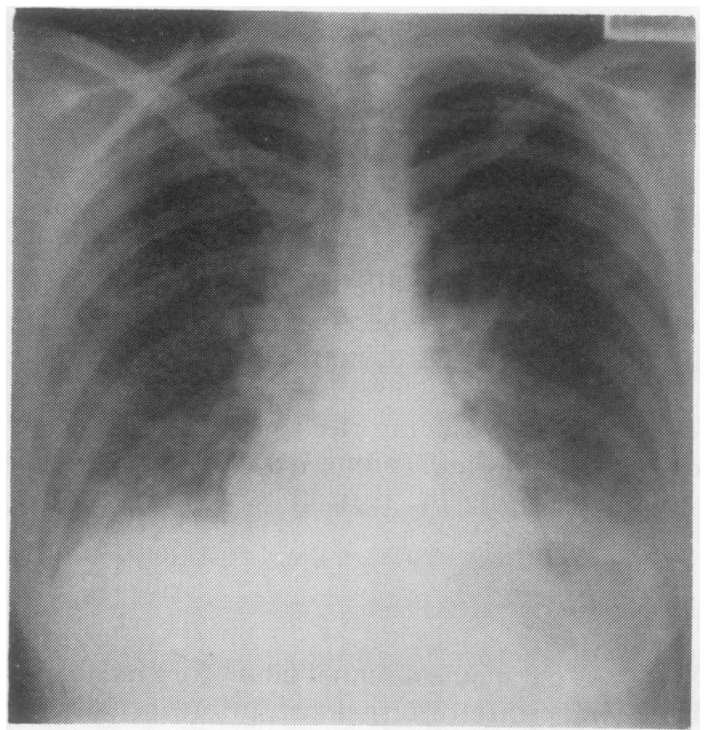

Fig 3 Chest radiograph 17 hours after challenge to Pauli's reagent showing bilateral diffuse small nodular opacities.

Lung function tests before and after challenge to Pauli's reagent

\begin{tabular}{|c|c|c|c|c|c|c|c|c|c|}
\hline & $\begin{array}{l}P E F R \\
(l / \min )\end{array}$ & $\begin{array}{l}F E V_{1} \\
(l)\end{array}$ & $\begin{array}{l}F V C \\
(l)\end{array}$ & $F E V \mid F V C \%$ & $\begin{array}{l}V C \\
(l)\end{array}$ & $\begin{array}{l}R V \\
(l)\end{array}$ & $\begin{array}{l}T L C \\
(l)\end{array}$ & $R V / T I C \%$ & $\begin{array}{l}\text { Transfer factor } \\
((\mathrm{mmol} / \mathrm{min} / \mathrm{kPa})\end{array}$ \\
\hline $\begin{array}{l}\text { Predicted normal } \\
11.5 .77 \\
18.5 .77 \text { pre-challenge } \\
18.5 .774 \text { h post-challenge } \\
25.5 .77 \\
1.6 .77 \\
13.7 .77 \\
13.9 .77 \\
10.1 .78 \\
18 \cdot 7 \cdot 78\end{array}$ & $\begin{array}{l}415 \\
420 \\
460 \\
400 \\
440 \\
475 \\
490 \\
495 \\
500 \\
520\end{array}$ & $\begin{array}{l}2 \cdot 65 \\
2 \cdot 21 \\
2 \cdot 16 \\
1 \cdot 74 \\
2 \cdot 00 \\
2 \cdot 4 \\
2 \cdot 6 \\
2 \cdot 9 \\
2 \cdot 75 \\
2 \cdot 75\end{array}$ & $\begin{array}{l}3 \cdot 11 \\
2 \cdot 21 \\
2 \cdot 16 \\
1 \cdot 75 \\
2 \cdot 00 \\
2 \cdot 65 \\
2 \cdot 75 \\
3 \cdot 1 \\
3 \cdot 14 \\
3 \cdot 00\end{array}$ & $\begin{array}{r}85 \\
100 \\
100 \\
99 \\
100 \\
91 \\
95 \\
94 \\
88 \\
92\end{array}$ & $\begin{array}{l}3 \cdot 11 \\
1 \cdot 54 \\
1 \cdot 43 \\
1 \cdot 76 \\
2 \cdot 31 \\
2 \cdot 42 \\
3 \cdot 1 \\
3 \cdot 1 \\
3 \cdot 19\end{array}$ & $\begin{array}{l}1 \cdot 52 \\
1 \cdot 56 \\
1 \cdot 67 \\
1 \cdot 60 \\
1 \cdot 41 \\
1 \cdot 2 \\
1 \cdot 29 \\
1 \cdot 13 \\
1 \cdot 46\end{array}$ & $\begin{array}{l}4 \cdot 88 \\
3 \cdot 10 \\
3 \cdot 1 \\
3 \cdot 36 \\
3 \cdot 72 \\
3 \cdot 62 \\
4 \cdot 29 \\
4 \cdot 21 \\
4 \cdot 65\end{array}$ & $\begin{array}{l}31 \\
50 \% \\
54 \% \\
48 \% \\
38 \% \\
33 \% \\
29 \% \\
27 \% \\
31 \%\end{array}$ & $\begin{array}{l}8 \cdot 7 \\
4 \cdot 0 \\
3 \cdot 8 \\
4 \cdot 9 \\
5 \cdot 1 \\
5 \cdot 5 \\
6 \cdot 3 \\
6 \cdot 7 \\
7 \cdot 4\end{array}$ \\
\hline
\end{tabular}

Conversion $\mathrm{mmol} / \mathrm{min} / \mathbf{k P a} \times 2 \cdot 98=\mathrm{ml} / \mathrm{min} / \mathrm{mm} \mathrm{Hg}$. 


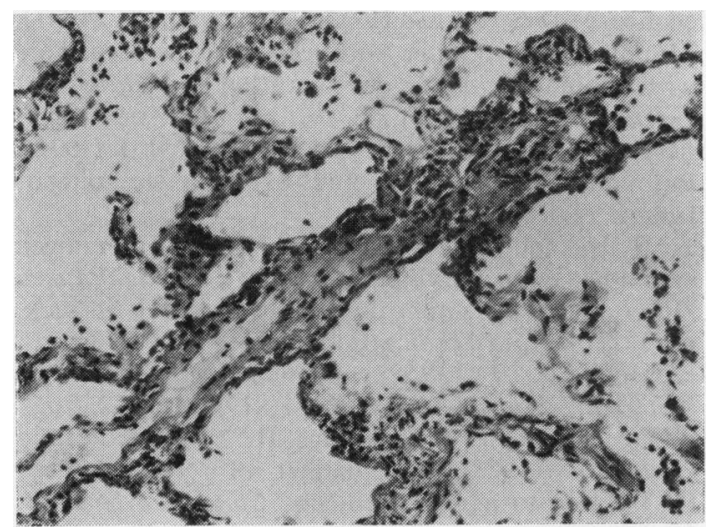

Fig 4 Drill biopsy specimen of lung tissue showing lymphocytic infiltration of thickened alveolar walls and occasional desquamated type 2 alveolar cells.

Haematoxylin and eosin $\times 120$ (original magnification).

evidence of emphysema or obliterative bronchiolitis. A peroxidase preparation showed fine immunoglobulin deposits within the alveolar walls. After the challenge serum complement concentrations were $\mathrm{CH} 50,25$ units (normal range 26-35 units), C3 $420 \mathrm{mg} / 1$ (700-1600 mg/l), and factor B $200 \mathrm{mg} / 1(100-400 \mathrm{mg} / \mathrm{l})$. Total levels of IgG, IgA, and IgM were normal but $\mathrm{IgE}$ was not assayed. Skin prick tests using control solution, sodium nitrite, sulphanilic acid $1 \%$, and the diazo reagent were performed on two normal subjects and the patient. All were negative apart from the diazo reagent skin test in the patient, which produced an immediate $5 \mathrm{~mm}$ weal and flare. There was little local itching and no late or dual response. The weal lasted for 12 hours and disappeared without leaving any scar or induration.

After the challenge test the patient was treated with prednisone $40 \mathrm{mg}$ daily for a week, and then in reducing dosages for a month when it was withdrawn. The chest radiograph cleared after five days. Her lung function tests gradually improved and after several months returned to normal though the improvement in the transfer factor was slow (table). She has had no further exposure to Pauli's reagent, and for the past nine months has been entirely symptom free.

\section{Discussion}

Pauli's reagent is widely used in laboratories as a dye in chromatography and other work to detect aryl amines and phenols. Despite this regular usage it has not previously been reported as producing pulmonary damage, and the precise mechanism in this patient remains unclear. Benzenesulphonic acid is chemically related to the sulphonamide nucleus, and these drugs are well known to produce pulmonary eosinophilia (Fiegenberg et al, 1967; Feinmann, 1975). There have also been reports linking the sulphonamides with both polyarteritis nodosa (Symmers, 1958) and a systemic lupus-like syndrome (Lee and Siegel, 1968), and more recently Thomas et al (1974) described a combined bronchial and alveolar response to the sulphonamide component in salazopyrine. Azo dyes have also been responsible for producing sensitisation reactions in both allergic and non-allergic subjects (Ferris et al, 1977; Alanko et al, 1978; Neuman et al, 1978). In fact azo compounds have for a long time been used for their immunogenic properties in animal research work.

In this patient hypersensitivity to the reagent, as opposed to a direct toxic effect, was suggested by the fact that colleagues working in the same environment failed to suffer from any adverse effects after exposure to the sprays, and had normal lung function tests. The histological findings of immunoglobulin deposits within the alveolar walls, the positive bronchial challenge, and the positive skin prick test indicate an immunologically mediated hypersensitivity mechanism. The low C3 component of the complement system with normal factor B suggest activation of the classical pathway, as found in antigen-antibody reactions. Although nitrous acid is produced as an intermediary in the formation of Pauli's reagent, there was no histological evidence of the emphysema or obliterative bronchiolitis that follows repeated exposure to nitrous fumes (McAdams, 1955; Becklake et al, 1957; Jones et al, 1973). The skin test response was reaginic in type such as those seen in classical IgE and IgG short-term sensitisation (IgGsts) mediated reactions (Parish, 1970; Bryant et al, 1973; Dolovich et al, 1973).

Interestingly this patient had both an immediate and late reaction. She is atopic and as such the immediate reaction was more likely to have been mediated via IgE rather than IgGsts. The late reaction and low $\mathrm{C} 3$, however, indicate that IgG was involved in part of her response. Probably the increased exposure to the reagent when the fume cupboard was defective in 1969 led to sensitisation and the production of IgE antibody, and that further low dose but regular exposure resulted in the production of IgG antibody and thus the alveolitis. The fact that this reaction has not previously been reported in a process so commonly used is probably a reflection of her atopic state with its increased susceptibility to sensitisation. 
We thank Dr Roger Seal for reporting on the lung biopsy and $\mathrm{Mr}$ Kelvin Houston and staff of the pulmonary function laboratory, Llandough Hospital, for their help.

\section{References}

Alanko, K, Keskinen, H, Björkstén, F, and Ojanen, S (1978). Immediate-type hypersensitivity to reactive dyes. Clinical Allergy, 8, 25-31.

Becklake, M R, Goldman, H I, Bosman, A R, and Freed, C C (1957). The long-term effects of exposure to nitrous fumes. American Review of Tuberculosis, 76, 398-408.

Bryant, D H, Burns, M W, and Lazarus, L (1973). New type of allergic asthma due to IgG "reaginic" antibody. British Medical Journal, 4, 589-592.

Dolovich, J, Hargreaves, F E, Chalmers, R, Shier, K J, Gauldie, J, and Bienenstock, J (1973). Late cutaneous allergic responses in isolated IgEdependent reactions. Journal of Allergy and Clinical Immunology, 52, 38-46.

Feinmann, L (1975). Lung parenchymal changes due to ingested substances. Proceedings of the Royal Society of Medicine, 68, 440-441.

Ferris, B G, Peters, J M, Burgess, W A, and Cherry, R B (1977). Apparent effect of an azodicarbonamide on the lungs. Journal of Occupational Medicine, 19, $424-425$.
Fiegenberg, D S, Weiss, H, and Kirshman, H (1967). Migratory pneumonia with eosinophilia associated with sulphonamide administration. Archives of $\frac{\bar{c}}{7}$ Internal Medicine, 120, 85-89.

Jones, G R, Proudfoot, A T, and Hall, J I (1973). Pulmonary effects of acute exposure to nitrous ${ }^{\text {s }}$ fumes. Thorax, 28, 61-65.

Lee, S L, and Siege, L M (1968). Drug-induced systemic lupus erythematosus. In Drug-induced $\vec{\omega}$ Diseases, vol 3, edited by L Meyler and H M Seck, p 239. Excerpta Medica Foundation, Amsterdam.

McAdams, A J (1955). Bronchiolitis obliterans. American Journal of Medicine, 19, 314-322.

Neuman, I, Elian, R, Nahum, H, Shaked, P, and Creter, D (1978). The danger of "yellow dyes" (tartrazine) to allergic subjects. Clinical Allergy, 8, 음 65-68.

Parish, W E (1970). Short term anaphylactic IgG antibodies in human sera. Lancet, 2, 591-592.

Sanerkin, N G, and Evans, D M D (1965). The sputum $\stackrel{\oplus}{-}$ in bronchial asthma; pathognomonic patterns. Journal of Pathology and Bacteriology, 89, 535-541.

Symmers, W St C (1958). Sensitivity Reactions to $\overrightarrow{0}$ Drugs, edited by M L Rosenheim and R Moulton. Blackwell, Oxford.

Thomas, P, Seaton, A, and Edwards, J (1974). Respiratory disease due to sulphasalazine. Clinical Allergy, 4, 41-47.

Requests for reprints to: Dr A Seaton, Institute of Occupational Medicine, 8 Roxburgh Place, Edinburgh. $\varrho$ 